CARDIOVASCULAR MEDICINE

\title{
Relation between $C$ reactive protein concentrations and coronary microvascular endothelial function
}

\author{
H Teragawa, Y Fukuda, K Matsuda, K Ueda, Y Higashi, T Oshima, M Yoshizumi, K Chayama
}

Heart 2004;90:750-754. doi: 10.1136/hrt.2003.022269

See end of article for authors' affiliations

Correspondence to:

Dr H Teragawa,

Department of Medicine

and Molecular Science,

Graduate School of

Biomedical Sciences,

Hiroshima University,

1-2-3 Kasumi, Minami-ku,

Hiroshima, Japan

734-8551; hteraga@

hiroshima-u.ac.jp

Accepted 5 February 2004

\begin{abstract}
Objective: To determine how $C$ reactive protein (CRP), a sensitive marker of inflammation, is related to coronary endothelial function.

Design: Changes in quantitative coronary angiographic findings and Doppler flow velocity measurements in response to locally infused acetylcholine were assessed.

Setting: Tertiary cardiology centre.

Patients: 46 patients with angiographically normal coronary arteries were divided into groups with normal ( $\leqslant 3 \mathrm{mg} / \mathrm{l}$ ) or increased ( $>3 \mathrm{mg} / \mathrm{l})$ CRP concentrations.

Interventions: Acetylcholine ( 3 and $30 \mu \mathrm{g} / \mathrm{min}$ ) was infused into the left coronary ostium for two minutes. Main outcome measures: Percentage change in diameter of epicardial coronary arteries and coronary blood flow (CBF) in response to acetylcholine; and correlations between these parameters and serum CRP concentrations.

Results: 15 patients had increased CRP concentrations. The change in coronary artery diameter induced by acetylcholine infusion was similar between the groups but the increase in CBF induced by acetylcholine was smaller in patients with increased CRP concentrations (54.9\% v 139.4\% with acetylcholine $30 \mu \mathrm{g} /$ $\min , p=0.0030$ ). Multivariate analysis identified increased CRP concentration as independently associated with attenuated CBF response to acetylcholine at $30 \mu \mathrm{g} / \mathrm{min}\left(\mathrm{p}=0.0078, R^{2}=0.434\right.$ ).

Conclusions: These findings suggest that inflammation appears to be associated with impaired coronary endothelial function in resistance but not conduit vessels. The data suggest a close relation between chronic vascular inflammation and endothelial dysfunction in atherosclerosis.
\end{abstract}

M uch interest has focused on the relation between vascular inflammation and atherosclerosis. ${ }^{1-3}$ The hypothesised initial event is impairment of endothelial function by any of several factors. A subsequent inflammatory response leads to atherosclerotic plaque development and eventually atherosclerosis. ${ }^{1-3}$ Thus, endothelial function may be closely related to chronic low grade inflammation. Several clinical studies have investigated the relation between peripheral endothelial function and inflammation $^{4-7}$ but much less is known about this relation in the coronary arteries.

$\mathrm{C}$ reactive protein $(\mathrm{CRP})$, the prototypic acute phase reactant, is synthesised in the liver. A sensitive marker of the inflammatory response, CRP is measured readily and is widely used clinically. ${ }^{8-10}$ To determine whether an inflammatory response is associated with impaired coronary endothelial function, we correlated CRP concentration with coronary endothelial function as determined by the response to intracoronary infusions of acetylcholine.

\section{METHODS}

\section{Study population}

We studied 46 Japanese patients (mean age 59 years, 30 men and 16 women) who underwent coronary angiography for evaluation of atypical chest pain. All patients had angiographically normal epicardial coronary arteries, normal left ventricular function (contrast ventriculographic ejection fraction $\geqslant 60 \%)$, and a normal coronary flow reserve $(>2.0)$. Patients with angiographically documented coronary spasm ( $>50 \%$ luminal narrowing) after intracoronary injection of acetylcholine, left ventricular hypertrophy, or valvar heart disease were excluded from the study. Patients with obvious systemic inflammatory diseases or possible acute systemic inflammation as suggested by a CRP concentration $>10 \mathrm{mg} / \mathrm{l}$ also were excluded. ${ }^{11}$ No patient with unstable angina was included. Written informed consent was obtained from all patients before entry into the study. The protocol was approved by the ethics committee of our institution.

\section{Study protocol}

All antianginal agents were discontinued at least 48 hours before catheterisation, except for unrestricted use of sublingual glyceryl trinitrate, which was withheld for one hour before catheterisation. Diagnostic left heart catheterisation and coronary angiography were performed by a standard percutaneous brachial approach. A 6 French guide catheter was introduced into the left main coronary artery. A 0.0014 inch Doppler flow guidewire (FloWire, Cardiometrics, Mountain View, California, USA) was advanced through the guide catheter into the proximal segment of the left anterior descending coronary artery. The wire tip was positioned in a straight segment of the vessel to obtain a reliable flow velocity signal.

After baseline control conditions were established, incremental doses of acetylcholine were infused into the left coronary artery ( 3 and $30 \mu \mathrm{g} / \mathrm{min}$ ) for two minutes, with five minute intervals between consecutive doses. After control conditions had been re-established, ATP $(20 \mu \mathrm{g})$ was infused. Finally, an intracoronary infusion of glyceryl trinitrate was given at a rate of $200 \mu \mathrm{g} / \mathrm{min}$ for one minute. Acetylcholine and glyceryl trinitrate were infused directly into the left coronary ostium with an infusion pump (TE-311, Terumo, Tokyo, Japan) at a rate of $1 \mathrm{ml} / \mathrm{min}$.

Coronary angiography was performed under control conditions and at the end of each drug infusion. Coronary blood flow (CBF) velocity was monitored continuously with a $12 \mathrm{MHz}$ pulsed Doppler velocimeter (FloMap, 
Cardiometrics). Arterial pressure, heart rate, and ECG were monitored continuously and recorded with a multichannel recorder (Polygraph 1600, Nihon Electric Corporation, Tokyo, Japan).

\section{Quantitative coronary angiography}

The method for measuring coronary diameter has been described previously in detail. ${ }^{12}{ }^{13}$ The coronary segment $2 \mathrm{~mm}$ distal to the Doppler wire tip was selected for quantitative analysis. In each patient, luminal diameters of selected segments of the left anterior descending coronary artery were measured by a single investigator blinded to angiographic and clinical data to determine the effects of different drugs on the epicardial coronary diameter. Luminal diameters were measured on an end diastolic frame by a computer assisted coronary angiographic analysis system (CAAS II/QUANTCOR, Siemens, Berlin, Germany). Means of triplicate measurements of luminal diameter were used for analysis. Changes in coronary diameter in response to acetylcholine and glyceryl trinitrate infusion are expressed as percentage change from the baseline measurement on the angiogram obtained before infusion. Intraobserver and interobserver variability previously were shown to be excellent. ${ }^{12} 13$

\section{Estimation of $C B F$ and coronary flow reserve}

$\mathrm{CBF}$ was calculated as the product of CBF velocity and vessel diameter according to the following formula: $\pi \times$ average peak velocity $\times 0.125 \times$ diameter $^{2}$. For CBF calculations, the internal diameter of the vessel at the location of the flow measurements ( $2 \mathrm{~mm}$ distal to the wire tip) was measured by the method described above. Coronary flow reserve was calculated as the ratio of CBF velocity after an injection of ATP to the baseline velocity.

\section{Biochemical parameters}

Fasting blood samples were obtained just before coronary angiography was performed. Routine methods were used to determine serum concentrations of standard biochemical parameters. CRP concentration was determined by a high sensitivity CRP test (N Latex CRP II, Dade Behring, Marburg, Germany). According to the manufacturer's information, the limit of detection in this assay is $0.02 \mathrm{mg} / \mathrm{l}$. The reported intra-assay coefficient of variation for high serum CRP concentrations is $1.5-2.4 \%$; for intermediate serum CRP concentrations, 2.8-4.7\%; and for low serum CRP concentrations, $1.5-4.6 \%$. The mean values of the coefficient of variation for measurements obtained over four days for high, moderate, and low serum CRP concentrations were $2.0 \%$, $2.4 \%$, and $2.8 \%$, respectively. Patients were divided into two groups depending on whether the CRP concentration was normal $(\leqslant 3 \mathrm{mg} / \mathrm{l})$ or increased $(>3 \mathrm{mg} / \mathrm{l})$.

\section{Statistical analysis}

All data are expressed as the mean (SEM). Baseline characteristics between the two groups were compared by Student's unpaired $t$ test or the $\chi^{2}$ analysis, as appropriate. Serial changes in haemodynamic variables and changes in coronary vasoreactivity in response to drug infusion were compared by a one way analysis of variance. If the analysis of variance showed a significant difference between means, the level of significance was determined by contrast analysis. Serial percentage changes in the coronary vascular response to acetylcholine infusion were compared between groups by a two way analysis of variance. We performed univariate and multivariate regression analyses to identify factors associated with percentage changes in CBF induced by acetylcholine. A probability value of $\mathrm{p}<0.05$ was considered to indicate significance.

\section{RESULTS}

Patient characteristics and biochemical parameters

Table I summarises the characteristics of patients. Fifteen patients had increased CRP concentrations. Distributions of age, sex, and body mass index in the two groups were similar. Frequencies of individual coronary risk factors and the numbers of patients who were taking aspirin or statins were also similar. Biochemical analysis showed that total cholesterol and low density lipoprotein cholesterol concentrations were higher, and high density lipoprotein cholesterol concentrations tended to be higher, in patients with increased CRP concentrations. The CRP concentration was $5.05(0.33) \mathrm{mg} / \mathrm{l}$ in patients with increased CRP concentrations and $0.35(0.23) \mathrm{mg} / \mathrm{l}$ in patients with normal CRP concentrations $(\mathrm{p}<0.0001)$.

\section{CRP concentration and coronary vasoreactivity}

Baseline heart rate and mean arterial pressure in the two groups were similar before and during acetylcholine infusion. Glyceryl trinitrate infusion increased heart rate and

\begin{tabular}{|c|c|c|c|}
\hline & $\begin{array}{l}\text { Increased CRP } \\
(n=15)\end{array}$ & $\begin{array}{l}\text { Normal CRP } \\
(n=31)\end{array}$ & $p$ Value \\
\hline Age (years) & $61(3)$ & $59(2)$ & NS \\
\hline Men/women & $8 / 7$ & $22 / 9$ & NS \\
\hline Body mass index $\left(\mathrm{kg} / \mathrm{m}^{2}\right)$ & $24.8(0.8)$ & $24.6(0.6)$ & NS \\
\hline \multicolumn{4}{|l|}{ Coronary risk factors } \\
\hline Smoking & $5(33 \%)$ & $8(26 \%)$ & NS \\
\hline Hypertension* ${ }^{*}$ & $5(33 \%)$ & $15(48 \%)$ & NS \\
\hline Hypercholesterolaemia & $8(53 \%)$ & $10(32 \%)$ & NS \\
\hline Total cholesterol $(\mathrm{mmol} / \mathrm{l})$ & $5.86(0.22)$ & $5.11(0.15)$ & 0.0079 \\
\hline Triglycerides $(\mathrm{mmol} / \mathrm{l})$ & $1.85(0.19)$ & $1.52(0.13)$ & NS \\
\hline $\mathrm{HDL}$ cholesterol (mmol/l) & $1.27(0.10)$ & $1.49(0.07)$ & 0.0848 \\
\hline LDL cholesterol (mmol/l) & $3.74(0.21)$ & $2.92(0.14)$ & 0.0024 \\
\hline Diabetes mellitus & $2(13 \%)$ & $4(13 \%)$ & NS \\
\hline Serum glucose $(\mathrm{mmol} / \mathrm{l})$ & $5.43(0.28)$ & $5.65(0.20)$ & NS \\
\hline \multicolumn{4}{|l|}{ Medications } \\
\hline Aspirin & $7(43 \%)$ & $13(42 \%)$ & NS \\
\hline Statin & $3(20 \%)$ & $5(16 \%)$ & NS \\
\hline High sensitive CRP (mg/l) & $5.05(0.33)$ & $0.34(0.23)$ & $<0.0001$ \\
\hline
\end{tabular}




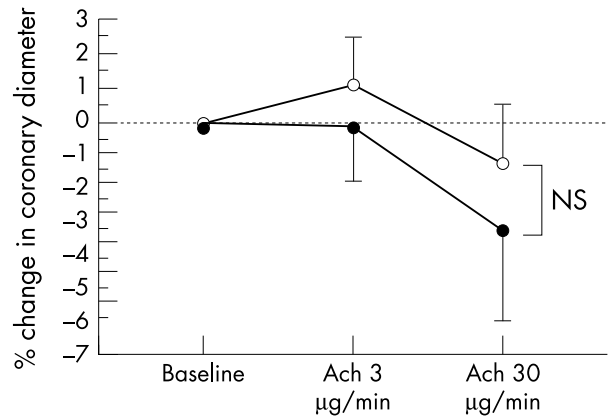

Figure 1 Percentage changes in epicardial coronary artery diameter in response to acetylcholine (ACh) infusion. The changes in coronary artery diameter in response to Ach infusion were similar between patients with increased $C$ reactive protein (CRP) concentrations (solid circles) and patients with normal CRP concentrations (open circles). Vertical bars represent SEM. NS, not significant.

decreased mean arterial pressure. Coronary artery diameter and CBF at baseline were similar between the two groups. Changes in the coronary diameter in response to acetylcholine infusion also were similar between the groups (fig 1 and table 2), but the increase in CBF in response to acetylcholine infusion was attenuated in patients with increased CRP concentrations relative to that in patients with normal CRP concentrations ( $p=0.0030$; fig 2 and table 2$)$. Coronary flow reserve was similar between the two groups (table 2), as was glyceryl trinitrate induced change in coronary diameter (table 2). Because the difference in coronary vasoreactivity between the two groups was greatest after infusion of acetylcholine at a dose of $30 \mu \mathrm{g} / \mathrm{min}$, in subsequent analyses we used the increase obtained with that dose.

\section{Factors associated with impaired coronary vasoreactivity}

On the basis of univariate analysis, factors associated with the increase in CBF induced by acetylcholine at $30 \mu \mathrm{g} / \mathrm{min}$ were male sex $(p=0.0157)$, increased CRP concentration $(p=0.0006)$, and coronary flow reserve $(p=0.0119)$. In addition, factors associated at $\mathrm{p}<0.2$ with the increase in CBF induced by acetylcholine at $30 \mu \mathrm{g} / \mathrm{min}$ were serum concentrations of triglyceride $(p=0.1156)$, high density lipoprotein cholesterol $(\mathrm{p}=0.1120)$, and low density lipoprotein cholesterol ( $\mathrm{p}=0.1932)$. Multivariate regression analysis of these factors showed that increased CRP concentration $(t=-2.81, \mathrm{p}=0.0078)$ and coronary flow reserve $(t=2.28, \mathrm{p}=0.0279)$ were associated with the

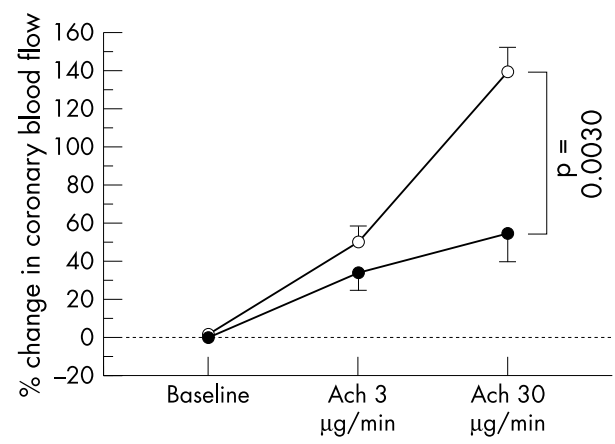

Figure 2 Percentage change in coronary blood flow (CBF) in response to $A C h$ infusion. The increase in $C B F$ in response to Ach infusion was attenuated in patients with increased CRP concentrations (solid circles) relative to that in patients with normal CRP concentrations (open circles). Vertical bars represent SEM.

increase in $\mathrm{CBF}$ induced by acetylcholine at $30 \mu \mathrm{g} / \mathrm{min}$ $\left(R^{2}=0.434\right)$.

\section{DISCUSSION}

The present study investigated the relation between coronary endothelial function and serum concentrations of CRP, a marker of inflammation, in patients with atypical chest pain and normal coronary arteries. We found that the acetylcholine induced increase in CBF was reduced in patients with increased CRP concentrations. Furthermore, multivariate regression analysis indicated that increased CRP concentration was independently associated with attenuation of the increase in $\mathrm{CBF}$ in response to acetylcholine infusion. Our results suggest that chronic low grade inflammation may be associated with microvascular coronary endothelial dysfunction.

\section{Previous studies on endothelial function and the inflammatory response}

Atherosclerosis has been suggested to be an inflammatory disease $\mathrm{e}^{1-3}{ }^{14}$ initiated by endothelial dysfunction caused by several risk factors. Subsequent vascular inflammation leads to an increased CRP concentration, either secondarily or with CRP as a direct participant in the inflammatory process, ${ }^{15}$ attenuating nitric oxide production in the endothelium. ${ }^{16}$ Irrespective of pathogenetic issues concerning CRP, several studies have established a close relation between endothelial function and the inflammatory response. ${ }^{4-7}$ Fichtlscherer et $\mathrm{al}^{4}$ and Sinisalo $e^{2} a^{6}$ have shown that CRP concentrations are

Table 2 Haemodynamic variables and coronary vasoreactivity

\begin{tabular}{|c|c|c|c|c|}
\hline & \multicolumn{2}{|l|}{ Increased CRP } & \multicolumn{2}{|l|}{ Normal CRP } \\
\hline & Value & $\%$ change & Value & $\%$ change \\
\hline Baseline mean blood pressure $(\mathrm{mm} \mathrm{Hg})$ & $112(4)$ & & $107(3)$ & \\
\hline Baseline heart rate (beats/min) & $68(3)$ & & $67(2)$ & \\
\hline \multicolumn{5}{|l|}{ Coronary diameter $(\mathrm{mm})$} \\
\hline Baseline & $3.12(0.14)$ & 0 & $3.12(0.10)$ & 0 \\
\hline Acetylcholine $3 \mu \mathrm{g} / \mathrm{min}$ & $3.13(0.15)$ & $-0.1(1.9)$ & $3.15(0.10)$ & $1.1(1.3)$ \\
\hline Acetylcholine $30 \mu \mathrm{g} / \mathrm{min}$ & $3.03(0.16)$ & $-3.3(2.5)$ & $3.08(0.11)$ & $-1.2(1.8)$ \\
\hline Glyceryl trinitrate & $3.54(0.13)^{*}$ & $15.3(3.4)^{*}$ & $3.51(0.09)^{*}$ & $13.0(2.4)^{*}$ \\
\hline \multicolumn{5}{|l|}{ Coronary blood flow $(\mathrm{ml} / \mathrm{min})$} \\
\hline Baseline & $68.5(8.6)$ & 0 & $79.0(6.0)$ & 0 \\
\hline Acetylcholine $3 \mu \mathrm{g} / \mathrm{min}$ & $93.5(15.3) \dagger$ & $34.0(11.7) \dagger$ & $118.1(10.6) \dagger$ & $50.6(8.2) \dagger$ \\
\hline Acetylcholine $30 \mu \mathrm{g} / \mathrm{min}$ & $107.8(21.7)^{\star} \ddagger$ & $54.9(18.8)^{*} \ddagger$ & $187.7(15.1)^{*}$ & $139.4(13.1)^{\star}$ \\
\hline Coronary flow reserve & $3.12(0.21)$ & & $3.28(0.15)$ & \\
\hline
\end{tabular}


associated with the intensity of the response of forearm blood flow to acetylcholine infusion in patients with coronary artery disease. Cleland et $a l^{5}$ have shown that the CRP concentration correlates with basal forearm blood flow in healthy patients by using $N^{\mathrm{G}}$-monomethyl-L-arginine, a nitric oxide synthase inhibitor. These findings suggest that the inflammation is associated with impaired endothelial function in resistance vessels, although differences in study populations may have contributed to basal or agonist induced endothelial dysfunction. In addition, Paisley et al observed endothelial dysfunction in conduit vessels in patients with asymptomatic proteinuria, although an inflammatory response was found only in resistance vessels. Thus, a low grade inflammatory response seems to be associated with impaired endothelial function, at least in resistance vessels. However, several studies examined relations between the inflammatory response and peripheral endothelial function. Only a single investigation addressed the relation between the inflammatory response and coronary vasoreactivity; that study was of patients with unstable angina. ${ }^{17}$

\section{Inflammatory response and coronary endothelial function}

Tomai et $a l^{17}$ reported that increased CRP concentrations were related to attenuation of changes in minimal epicardial coronary artery diameter during the cold pressor test in patients with unstable angina; this suggested that increased CRP concentration was associated with enhanced vasoreactivity at the site of the culprit lesion. Several modulators may affect vasoreactivity at the involved site in unstable angina and endothelial function presumably was not the sole influence on local coronary vasoreactivity. On the other hand, when we investigated the relation between CRP concentration and acetylcholine induced coronary vasoreactivity in patients with atypical chest pain and normal coronary arteries, we were able to investigate the relation between the inflammatory response and coronary endothelial function without the complexities introduced by an established lesion.

The present study showed that CRP concentrations were not associated with acetylcholine induced change in coronary diameter but did influence the degree of acetylcholine induced increase in CBF independently of coronary flow reserve. In previous studies, ${ }^{18}{ }^{19}$ the acetylcholine induced increase in $\mathrm{CBF}$ was reduced by an infusion of $N^{\mathrm{G}}$ monomethyl-L-arginine, indicating that endothelial nitric oxide has at least some role in the $\mathrm{CBF}$ response to acetylcholine infusion. Thus, our results suggest that an inflammatory response is associated with coronary endothelial dysfunction at the level of resistance vessels. The exact mechanisms linking CRP concentration with microvascular endothelial function are unclear. The mean CRP concentration in this study was less increased than that observed in the report ${ }^{17}$ concerning unstable angina; indeed, because CRP is increased in patients with unstable angina, ${ }^{20}$ we excluded patients with this possible diagnosis. In addition, our study population had no evidence of atherosclerotic lesions on angiography. Such differences may have influenced our results.

\section{Relation between the CRP concentration and other parameters}

In the present study, total cholesterol and low density lipoprotein cholesterol concentrations were increased in patients with increased CRP concentrations, essentially in agreement with previous reports. ${ }^{21} 22$ The reasons why CRP concentration correlates with lipid concentrations are unclear. However, lipid increase is a coronary risk factor and is known to impair endothelial function. ${ }^{1323} 24$ Since CRP is a marker of endothelial dysfunction, CRP may correlate with lipids on that basis. On the other hand, our results did not show a relation between CRP and body mass index, as reported from other studies. ${ }^{21}{ }^{25}$ Our subject population was not obese, which may account for this difference.

Recently, much interest has focused on the anti-inflammatory effect of statins. ${ }^{26}{ }^{27}$ In addition, use of low dose aspirin may reduce CRP concentrations ${ }^{28} 29$ in patients with coronary artery disease, while aspirin has no effect on CRP in healthy patients. ${ }^{30}$ The present study failed to find any relation between the use of these drugs and CRP concentration or coronary vasoreactivity. Differences in patient characteristics and in doses and duration of drug treatment may account for a lack of a drug effect here.

\section{Study limitations}

Several limitations to the present study should be considered. Firstly, the relatively small number of patients may have obscured relations between CRP concentration and some other variables (type II error). Secondly, while our study population was a homogeneous group with atypical chest pain, angiographically normal coronary arteries, normal left ventricular function, and no vasospastic or unstable angina, a wholly homogeneous underlying disease state cannot be guaranteed. Occult variability, then, may have contributed to variability in CRP concentration. Thirdly, in the measurement of CRP, the use of two samples has been recommended, ${ }^{11}$ but we measured CRP only once. In addition, we divided patients into two groups depending on whether the CRP concentration was normal $(\leqslant 3 \mathrm{mg} / \mathrm{l})$ or increased $(>3 \mathrm{mg} / \mathrm{l})$. However, patients with a CRP concentration of $1.0-3.0 \mathrm{mg} /$ $\mathrm{l}$, who would fall into our "normal CRP concentration" group, have been shown to have a moderate relative risk of future cardiovascular events. ${ }^{11}$ Therefore, we need to reassess the relation between coronary endothelial function and CRP concentration based on the relative risk categories. ${ }^{11}$ Lastly, patients with obvious systemic inflammation or acute infection were excluded from the study, since systemic inflammation or acute infection may affect not only CRP concentration but also endothelial function. ${ }^{31-33}$ Yet we did not perform a thorough medical investigation aimed at uncovering all possible sources of inflammation, so increased CRP concentrations may have resulted from systemic inflammation in some patients.

\section{Conclusions}

Our present findings indicate that a chronic low grade inflammatory response is associated with microvascular coronary endothelial dysfunction. These findings support a close relation between endothelial dysfunction and vascular inflammation in the pathogenesis of atherosclerosis.

\section{ACKNOWLEDGEMENTS}

We are grateful to Fumiharu Miura MD, Sou Takenaka MD, and Masayuki Katsumoto MD of the Department of Medicine and Molecular Science, Graduate School of Biomedical Sciences, Hiroshima University, for their technical assistance and helpful comments. We also thank Yuko Omura for her secretarial assistance.

\section{Authors' affiliations}

H Teragawa, Y Fukuda, K Matsuda, K Ueda, K Chayama, Department of Medicine and Molecular Science, Graduate School of Biomedical Sciences, Hiroshima University, Hiroshima, Japan

Y Higashi, M Yoshizumi, Department of Cardiovascular Physiology and Medicine, Graduate School of Biomedical Sciences, Hiroshima University

T Oshima, Department of Clinical Laboratory Medicine, Graduate School of Biomedical Sciences, Hiroshima University 


\section{REFERENCES}

1 Ross R. Atherosclerosis: an inflammatory disease. N Engl J Med 1999:340:115-26.

2 Kinlay S, Libby P, Ganz P. Endothelial function and coronary artery disease. Curr Opin Lipidol 2001;12:383-9.

3 Libby P. Inflammation in atherosclerosis. Nature 2002;420:868-74.

4 Fichtlscherer S, Rosenberger G, Walter DH, et al. Elevated C-reactive protein levels and impaired endothelial vasoreactivity in patients with coronary artery disease. Circulation 2000;102:1000-6.

5 Cleland SJ, Sattar N, Petrie JR, et al. Endothelial dysfunction as a possible link between C-reactive protein levels and cardiovascular disease. Clin Sci (Colch) 2000;98:531-5

6 Sinisalo J, Paronen J, Mattila KJ, et al. Relation of inflammation to vascular function in patients with coronary heart disease. Atherosclerosis 2000; 149:403-11.

7 Paisley KE, Beaman M, Tooke JE, et al. Endothelial dysfunction and inflammation in asymptomatic proteinuria. Kidney Int 2003;63:624-33.

8 Ridker PM, Cushman M, Stampfer MJ, et al. Inflammation, aspirin, and the risk of cardiovascular disease in apparently healthy men. N Engl J Med 1997;336:973-9.

9 Ridker PM, Hennekens $\mathrm{CH}$, Buring JE, et al. C-reactive protein and other markers of inflammation in the prediction of cardiovascular disease in women. N Engl J Med 2000;342:836-43

10 Ridker PM. High-sensitivity C-reactive protein: potential adjunct for global risk assessment in the primary prevention of cardiovascular disease. Circulation 2001;103:1813-8.

11 Pearson TA, Mensah GA, Alexander RW, et al. Markers of inflammation and cardiovascular disease: application to clinical and public health practice: a statement for healthcare professionals from the Centers for Disease Control and Prevention and the American Heart Association. Circulation 2003; 107:499-511

12 Teragawa $\mathrm{H}$, Kato $M$, Yamagata T, et al. Magnesium causes nitric oxide independent coronary artery vasodilation in humans. Heart 2001;86:212-6.

13 Fukuda Y, Teragawa H, Matsuda K, et al. Tetrahydrobiopterin restores endothelial function of coronary arteries in patients with hypercholesterolaemia. Heart 2002;87:264-9.

14 Libby P. Current concepts of the pathogenesis of the acute coronary syndromes. Circulation 2001;104:365-72.

15 Bharadwaj D, Stein MP, Volzer M, et al. The major receptor for C-reactive protein on leukocytes is fcgamma receptor II. J Exp Med 1999; 190:585-90.

16 Verma S, Wang $\mathrm{CH}$, Li SH, et al. A self-fulfilling prophecy: C-reactive protein attenuates nitric oxide production and inhibits angiogenesis. Circulation 2002;106:913-9.

17 Tomai F, Crea F, Gaspardone A, et al. Unstable angina and elevated c-reactive protein levels predict enhanced vasoreactivity of the culprit lesion. Circulation 2001; 104:1471-6.
18 Quyyumi AA, Dakak N, Mulcahy D, et al. Nitric oxide activity in the atherosclerotic human coronary circulation. J Am Coll Cardiol 1997;29:308-17

19 Tagawa T, Mohri M, Tagawa H, et al. Role of nitric oxide in substance P-induced vasodilation differs between the coronary and forearm circulation in humans. J Cardiovasc Pharmacol 1997;29:546-53.

20 Versaci F, Gaspardone A, Tomai F, et al. Predictive value of C-reactive protein in patients with unstable angina pectoris undergoing coronary artery stent implantation. Am J Cardiol 2000;85:92-5, A8.

21 Chambers JC, Eda S, Bassett $\mathrm{P}$, et al. C-reactive protein, insulin resistance, central obesity, and coronary heart disease risk in Indian Asians from the United Kingdom compared with European whites. Circulation 2001;104:145-50.

22 Ridker PM. Clinical application of C-reactive protein for cardiovascular disease detection and prevention. Circulation 2003;107:363-9.

23 Shiode N, Nakayama K, Morishima N, et al. Nitric oxide production by coronary conductance and resistance vessels in hypercholesterolemia patients. Am Heart J 1996;131:1051-7.

24 Capell WH, DeSouza CA, Poirier P, et al. Short-term triglyceride lowering with fenofibrate improves vasodilator function in subjects with hypertriglyceridemia. Arterioscler Thromb Vasc Biol 2003;23:307-13.

25 Lemieux I, Pascot A, Prud'homme D, et al. Elevated C-reactive protein: another component of the atherothrombotic profile of abdominal obesity Arterioscler Thromb Vasc Biol 2001;21:961-7.

26 Horne BD, Muhlestein JB, Carlquist JF, et al. Statin therapy, lipid levels, $C$-reactive protein and the survival of patients with angiographically severe coronary artery disease. J Am Coll Cardiol 2000;36:1774-80.

27 Albert MA, Danielson E, Rifai N, et al. Effect of statin therapy on C-reactive protein levels: the pravastatin inflammation/CRP evaluation (PRINCE): a randomized trial and cohort study. JAMA 2001;286:64-70

28 Ikonomidis I, Andreotti F, Economou E, et al. Increased proinflammatory cytokines in patients with chronic stable angina and their reduction by aspirin. Circulation 1999:100:793-8.

29 Kennon S, Price CP, Mills PG, et al. The effect of aspirin on C-reactive protein as a marker of risk in unstable angina. J Am Coll Cardiol 2001;37:1266-70.

30 Feldman M, Jialal I, Devaraj S, et al. Effects of low-dose aspirin on serum C-reactive protein and thromboxane B2 concentrations: a placebo-controlled study using a highly sensitive C-reactive protein assay. J Am Coll Cardiol 2001;37:2036-41.

31 Raza K, Thambyrajah J, Townend JN, et al. Suppression of inflammation in primary systemic vasculitis restores vascular endothelial function: lessons for atherosclerotic disease? Circulation 2000;102:1470-2.

32 Hingorani AD, Cross J, Kharbanda RK, et al. Acute systemic inflammation impairs endothelium-dependent dilatation in humans. Circulation 2000;102:994-9

33 Kharbanda RK, Walton B, Allen M, et al. Prevention of inflammation-induced endothelial dysfunction: a novel vasculo-protective action of aspirin. Circulation 2002;105:2600-4.

\section{ELECTRONIC PAGES}

\section{Heart Online case reports: www.heartinl.com}

$7 \mathrm{c}$ he follow electronic only articles are published in conjunction with this issue of Heart.

\section{Massive pulmonary embolism with ST elevation in leads V1-V3 and successful thrombolysis with tenecteplase}

I G Livaditis, M Paraschos, K Dimopoulos

A 42 year old woman was referred to the emergency department from the radiology department after having a syncopal episode during a triplex examination of the lower extremities for acute painful right leg swelling five hours earlier that morning. She had no significant medical history, smoked 3-5 cigarettes a day, and had been taking contraceptive medication for menorrhagia for the preceding three months. On presentation she was cyanotic, dyspnoeic, and haemodynamically unstable. ECG showed sinus tachycardia of 120 beats/min with ST elevations from V1 through V3 mimicking anteroseptal acute myocardial infarction. Ten minutes after presentation she was thrombolysed with $80 \mathrm{mg}$ tenecteplase leading to ST elevation resolution and remarkable haemodynamic recovery after 20 minutes. This case shows how pulmonary embolism can mimic anteroseptal acute myocardial infarction on ECG and the life saving results from rapid thrombolysis with tenecteplase.

(Heart 2004;90:e41) www.heartjnl.com/cgi/content/full/90/ $7 / \mathrm{e} 41$

\section{Fatal pulmonary arterial hypertension associated with phenylpropanolamine exposure}

\section{R J Barst, L Abenhaim}

Exogenous substances such as the appetite suppressant fenfluramine are known to be causally related to the development of pulmonary arterial hypertension (PAH). In these cases, the clinical course as well as the pulmonary vascular disease pathologically is indistinguishable from idiopathic PAH. Other exogenous substances, such as amphetamines, cocaine, and meta-amphetamines, have been considered to be potential risk factors for inducing PAH. SOPHIA (the study of pulmonary hypertension in America), in addition to confirming previous reports of a causal association between the appetite suppressant fenfluramine and PAH, unexpectedly found a significantly increased risk for the development of PAH with exposure to over-thecounter antiobesity agents containing phenylpropanolamine. The first case is reported of fatal PAH in a child heavily treated with cold remedies containing phenylpropanolamine, which, in addition to the results of SOPHIA, strengthens the hypothesis that phenylpropanolamine is a risk factor for the development of PAH.

(Heart 2004;90:e42) www.heartjnl.com/cgi/content/full/90/ 7/e42 